\title{
octanate $^{\circledR}$ : over 20 years of clinical experience in overcoming challenges in haemophilia A treatment
}

\author{
Anna Klukowska, Vladimír Komrska, Vladimír Vdovin, Nadezhda Zozulya, \\ Toshko Lissitchkov, Johannes Oldenburg and Carmen Escuriola Ettingshausen
}

\begin{abstract}
Treatment of haemophilia A with FVIII replacement has evolved over the past decades to adapt to the needs of patients. octanate ${ }^{\circledR}$, a plasma-derived, double virusinactivated, von Willebrand factor (VWF)-containing FVIII concentrate, has been used in clinics worldwide for over 20 years. First licensed in 1998 in Germany, octanate ${ }^{\circledR}$ is approved in over 80 countries for the prevention and treatment of bleeding and for surgical prophylaxis in patients with haemophilia $A$, and in over 40 countries for immune tolerance induction (ITI). The manufacturing process for octanate ${ }^{\circledR}$ was developed to ensure high viral safety and effectively eliminates both enveloped and nonenveloped viruses. Over the past 20 years, the excellent safety and efficacy of octanate ${ }^{\circledR}$ have been demonstrated in pivotal clinical trials in adult and paediatric previously treated patients (PTPs) for on-demand treatment, prophylaxis and as surgical cover. Importantly, octanate ${ }^{\circledR}$ has displayed low immunogenicity in previously untreated patients (PUPs), with only $9.8 \%$ of PUPs developing FVIII inhibitors. octanate ${ }^{\circledR}$ has also shown to be highly effective in inhibitor elimination when used as ITI therapy. In a population of patients with high risk of ITI failure, success was achieved in $79.2 \%$ of patients (70.8\% complete success), even when using exceptionally stringent success criteria. No relapses were observed. Here we present an overview of the clinical data with octanate ${ }^{\circledR}$ that support its use in a range of patient populations and clinical indications.
\end{abstract}

Keywords: haemophilia A, immune tolerance induction, octanate ${ }^{\circledR}$

Received: 14 November 2019; revised manuscript accepted: 18 February 2020.

\section{Introduction}

Haemophilia A is a bleeding disorder characterized by a deficiency of coagulation factor VIII (FVIII), and the natural approach to haemophilia management is replacement of the missing FVIII. Historically, FVIII replacement therapy required administration of whole fresh blood, fresh or frozen plasma or cryoprecipitate. In the 1970s, freezedried concentrates of coagulation factors from human plasma became commercially available, which represented the start of a new era of haemophilia therapy. The availability of factor concentrates dramatically increased access to replacement therapy, made home-based therapy feasible and resulted in improvements in life expectancy and quality of life for patients with haemophilia. ${ }^{1}$
Development of the solvent/detergent (S/D) viral inactivation method revolutionized the production of FVIII concentrates. This innovative approach, which inactivates lipid-enveloped viruses, was first employed on an industrial scale in the production of plasma-derived biopharmaceuticals by Octapharma in 1986. Subsequently, Octapharma further optimized the manufacture of their FVIII concentrates and included a second virus inactivation step of terminal dry-heat treatment in the production of octanate ${ }^{\circledR}$.

octanate $^{\circledR}$ is a native, human, highly purified plasma-derived (pd) FVIII/von Willebrand factor (VWF) concentrate that combines VWF ristocetin cofactor activity (VWF:RCo) and FVIII activity
Ther Adv Hematol

2020, Vol. 11: 1-12

DOI: $10.1177 /$

2040620720914692

(c) The Author(s), 2020. Article reuse guidelines: sagepub.com/journalspermissions
Correspondence to: Carmen Escuriola Ettingshausen

Haemophilia Centre Rhine Main $\mathrm{GmbH}$, Hessenring

13a, Geb. G, Mörfelden-

Walldorf, 64546, Germany carmen.escuriolada hzrm.de

Anna Klukowska Department of Paediatric

Oncology, Medical

University of Warsaw

Haematology, Clinical

Transplantology and

Paediatrics, Warsaw,

Poland

Vladimír Komrska

Department of Paediatric Hematology and Oncology, University Hospital Motol,

Prague, Czech Republic

Vladimír Vdovin

Morozovskaya Children's Hospital, Moscow, Russian

Federation

Nadezhda Zozulya

National Research Centre for Hematology, Moscow, Russian Federation

Toshko Lissitchkov Department of Disorders of Haemostasis, SBALHZ $E A D$, Sofia, Bulgaria

Department of Clinical Haematology in Haemorrhagic Diathesis and Anaemia, Specialized Hospital for Active Treatment "Joan Pavel", Sofia, Bulgaria

Johannes Oldenburg Institute of Experimental Haematology and Transfusion Medicine, University Clinic Bonn, Bonn, Germany 
(FVIII:C) in a ratio of $\sim 0.4$. FVIII binding to its natural stabilizer VWF may decrease FVIII immunogenicity due to epitope masking and protection of FVIII from endocytosis by antigenpresenting cells. ${ }^{2,3}$ Binding of FVIII to VWF also prolongs FVIII half-life by preventing its proteolytic degradation. ${ }^{4,5}$

octanate $^{\circledR}$ is derived from plasma from carefully selected donors and collected at highly regulated blood and plasma collection centres. Each individual donation undergoes virus testing for human immunodeficiency virus (HIV), hepatitis A, B and $\mathrm{C}$ viruses (HAV, HBV and HCV), and parvovirus B19. Only donations that are free from viruses are released for production. In addition to the extensive viral inactivation steps during its purification, the final octanate ${ }^{\circledR}$ product meets the European Medicines Agency standards for virus safety.

Over the 20 years since octanate ${ }^{\circledR}$ was first marketed in Germany in 1998, a wealth of data has been accumulated in clinical studies and in routine clinical practice demonstrating the efficacy and safety of octanate $^{\circledR}$ in previously treated patients (PTPs) with or without inhibitors, and previously untreated patients (PUPs). Since its development, over 12 billion IU of octanate ${ }^{\circledR}$ have been infused worldwide. Today, octanate ${ }^{\circledR}$ is approved in over 80 countries for the treatment and prevention of bleeding, including surgical prophylaxis, in patients with haemophilia $\mathrm{A}$, and in more than 40 countries for immune tolerance induction (ITI).

\section{Clinical development of octanate ${ }^{\circledR}$ : the clinical trial programme}

An extensive phase III programme was undertaken to investigate the efficacy, safety and pharmacokinetics of octanate ${ }^{\circledR}$ in a variety of clinical settings. Six prospective, open-label, noncontrolled, pivotal studies were conducted in accordance with good clinical practice guidelines. Five of these studies recruited a total of 86 PTPs (children, adolescents and adults) and one study was conducted in 51 PUPs (Table 1). Baseline demographics and clinical characteristics of the pooled PTP population and the PUPs are shown in Table 2.

At the time the pivotal studies were started (late 1990s and early 2000s), severe haemophilia A was defined as FVIII activity (FVIII:C) $<2 \%$.
The definition of severe haemophilia was later revised to FVIII:C $<1 \%$. Even so, $97 \%$ of PTPs in the pivotal studies had a basal FVIII:C of $\leqslant 1 \%$. In study AVI- $403,92 \%$ of the PUPs had FVIII:C $<1 \%$.

Three studies assessed the pharmacokinetic properties of octanate ${ }^{\circledR}$ as a primary objective; data are summarised in Table 3. The mean half-life of octanate $^{\circledR}$ after a single administration of an average dose of $40 \mathrm{IU} / \mathrm{kg}$ in PTPs $\geqslant 12$ years of age was between 11.1 and $14.3 \mathrm{~h},{ }^{6}$ and the mean recovery of octanate ${ }^{\circledR}$ was in agreement with expected recovery values for FVIII $(2.0-2.5 \%$ per $\mathrm{IU} / \mathrm{kg}) .{ }^{7}$ Mean recovery of octanate ${ }^{\circledR}$ in children under 6 years of age was analysed as a secondary objective in one PTP study and was slightly lower than that in adolescents and adults, as expected due to higher plasma volumes per unit weight in children. 8,9

All six studies assessed the efficacy, safety and immunogenicity of octanate ${ }^{\circledR}$ treatment, either prophylactically or on-demand, with immunogenicity being the primary endpoint in two PTP studies and the PUP study.

\section{octanate ${ }^{\circledR}$ is effective for the treatment and prevention of bleeding in PTPs}

The efficacy of octanate ${ }^{\circledR}$ in the treatment of bleeding episodes across the five PTP studies was assessed in a pooled analysis, based on the following objective criteria: percentage of bleeds treated successfully (see Figure 1 footnote for criteria), and percentage of bleeds with adequate treatment duration [defined as $\leqslant 2$ treatment days for bleeding episodes ( $\leqslant 7$ days for GI bleeding episodes)]. Across the five studies, 76 of the 77 patients experienced 1875 bleeding episodes. The success rate for octanate ${ }^{\circledR}$ treatment for all bleeding episodes was $92.7 \%$ [ $95 \%$ confidence interval (CI): $91.5 \%$, 93.9\%] and percentage of bleedings with adequate treatment duration was $94.7 \%(95 \% \mathrm{CI}$ : $93.6 \%, 95.6 \%)$. The percentage of bleeding episodes treated for $\leqslant 2$ days was $90.8 \%$. When only those bleeding episodes that were treated successfully were taken into consideration, the percentage of bleeds treated in $\leqslant 2$ days was $97.9 \%$ (Figure 1). The mean (SD) dose per day for successfully treated bleeds was $22.84(8.96) \mathrm{IU} / \mathrm{kg}$.

In three studies, including a paediatric study, (AVI-402, -406, -408), the efficacy of individual 


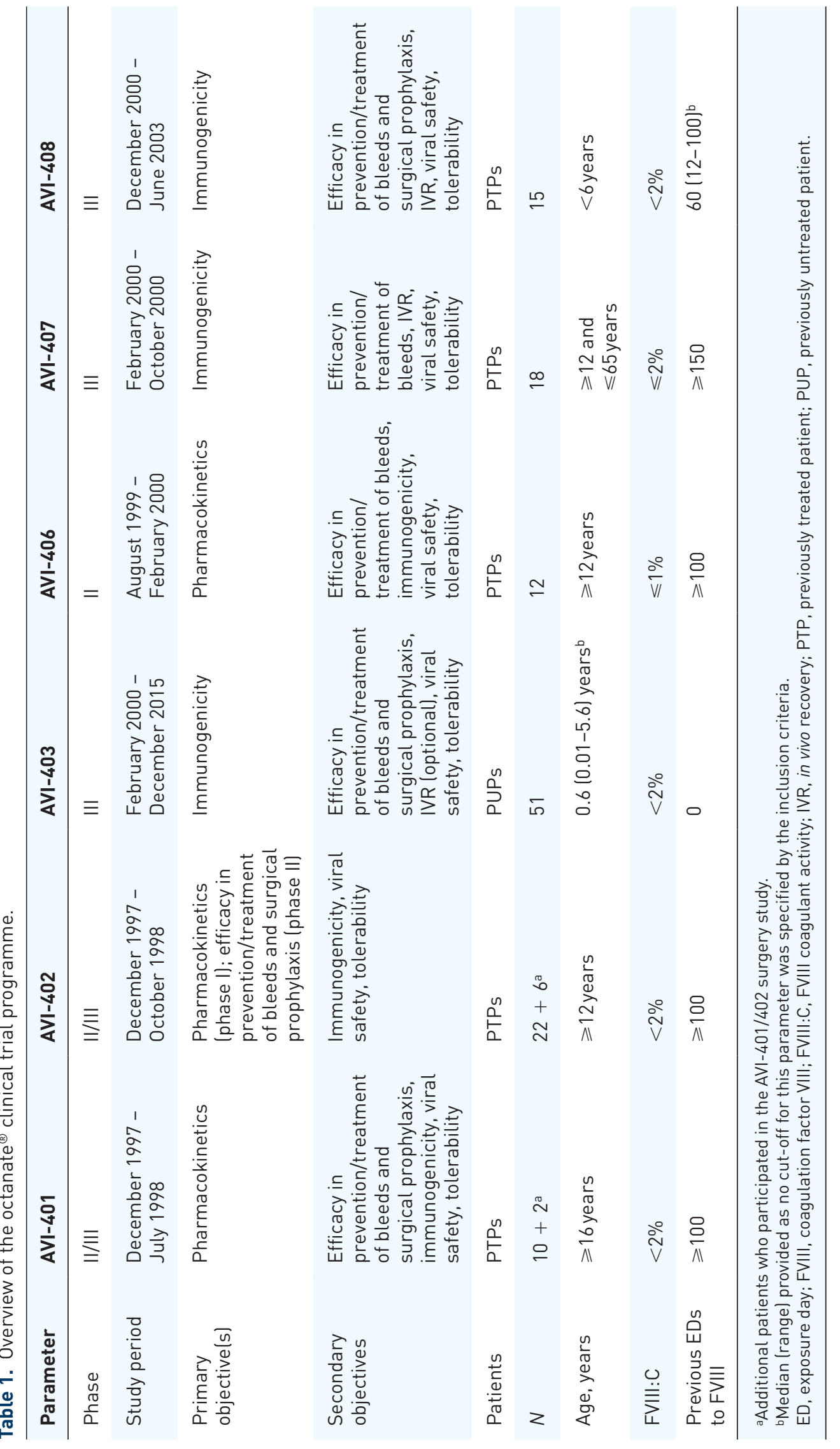


Table 2. Demographic and baseline characteristics in PTP (pooled) and PUP studies.

\begin{tabular}{lll}
\hline Parameter & $\begin{array}{l}\text { Pooled PTP studies (AVI-401, -402, } \\
\mathbf{- 4 0 6 , - 4 0 7 , - 4 0 8 )}\end{array}$ & PUP study (AVI-403) \\
\hline$N$ & 77 & 51 \\
Age, years & $22.2(1-54)$ & $0.81(0.01-5.6)$ \\
Height, cm & $158.3(76-197)$ & $72.4(50-118)$ \\
Weight, kg & $57.0(11-110)$ & $9.0(3-21)$ \\
Caucasian ethnicity, $N(\%)$ & N/A & $51(100)$ \\
FVIII:C, $N(\%)$ & & \\
$<1 \%$ & $11(14.3)$ & $47(92.2)$ \\
$\quad \leqslant 1 \%$ & $75(97.4)$ & $48(94.1)$ \\
$>1 \%$ to $\leqslant 2$ & $2(2.6)$ & $3(5.9)$ \\
Inhibitor titre $<0.6 \mathrm{BU} / \mathrm{mL}, N(\%)$ & $77(100)$ & $51(100)$ \\
\hline
\end{tabular}

Data are presented as mean (range) unless otherwise indicated.

BU, Bethesda units; FVIII:C, factor VIII coagulant activity; N/A, not available; PTP, previously treated patient; PUP, previously untreated patient.

Table 3. Pharmacokinetic results in PTP studies.

\begin{tabular}{|c|c|c|c|c|}
\hline \multirow[t]{2}{*}{ Parametera } & \multirow[t]{2}{*}{$\begin{array}{l}\text { AVI-401 } \\
(N=10)\end{array}$} & \multirow[t]{2}{*}{$\begin{array}{l}\text { AVI-402 } \\
(N=14)\end{array}$} & \multicolumn{2}{|l|}{$\begin{array}{l}\text { AVI-406 } \\
(N=12)^{b}\end{array}$} \\
\hline & & & Austria & France \\
\hline $\begin{array}{l}A \cup C_{\text {norm }} \\
\mathrm{h} \mathrm{IU} / \mathrm{mL} /(I \mathrm{I} / \mathrm{kg})\end{array}$ & $45.5 \pm 17.2$ & $33.4 \pm 8.5$ & $37.2 \pm 11.7$ & $36.3 \pm 11.8$ \\
\hline $\begin{array}{l}\text { Half-life } \\
\text { h }\end{array}$ & $14.3 \pm 4.0$ & $12.6 \pm 3.0$ & $11.1 \pm 4.3$ & $11.4 \pm 4.6$ \\
\hline $\begin{array}{l}\text { Clearance } \\
\mathrm{mL} / \mathrm{h} / \mathrm{kg}\end{array}$ & $2.6 \pm 1.2$ & $3.2 \pm 0.9$ & $3.0 \pm 1.3$ & $3.1 \pm 1.2$ \\
\hline $\begin{array}{l}\text { IVR } \\
\% \text { per IU/kg }\end{array}$ & $2.4 \pm 0.4$ & $2.4 \pm 0.3$ & $2.4 \pm 0.3$ & $2.2 \pm 0.3$ \\
\hline \multicolumn{5}{|c|}{$\begin{array}{l}\text { aData are expressed as mean } \pm \text { SD measured by the chromogenic assay. } \\
\text { bStudy AVI- } 406 \text { compared the PK parameters of octanate }{ }^{\circledR} \text { produced at a site in Austria las used in studies AVI-401 and } \\
-402 \text { ) with octanate }{ }^{\circledR} \text { manufactured at a production site that had recently been established in France. } \\
\text { AUC }_{\text {norm, }} \text { area under the curve normalised to the dose administered; IU, international unit; IVR, in vivo recovery; PTP, } \\
\text { previously treated patient; SD, standard deviation. }\end{array}$} \\
\hline
\end{tabular}

prophylactic infusions of octanate ${ }^{\circledR}$ was rated by the investigator. A total of 443 prophylactic infusions in 32 patients were rated for efficacy and $100 \%$ of these were rated as 'excellent'.

For long-term prophylaxis against bleeding in patients with severe haemophilia A, doses of
$20-40 \mathrm{IU} / \mathrm{kg}$ at intervals of $2-3$ days are recommended. ${ }^{10}$ Dosing of octanate ${ }^{\circledR}$ can also be personalized based on a patient's pharmacokinetic profile. The Web-Accessible Population Pharmacokinetic Service (WAPPS-Hemo; www.wappshemo.org), led by McMaster University, Hamilton, Ontario, Canada, ${ }^{11,12}$ allows the estimation of 


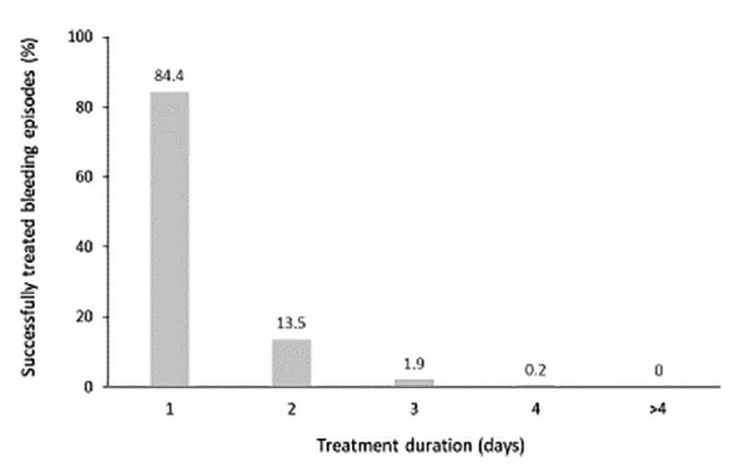

Figure 1. Proportions of bleeding episodes successfully treated with octanate ${ }^{\circledR}$ by treatment duration in PTPs. The treatment of a bleeding episode was classified as successful if none of the following criteria applied: additional treatment with another FVIII-containing product, excluding whole blood; blood transfusion required; follow-up treatment with a daily dose of octanate ${ }^{\circledR}>50 \%$ above the initial dose for episodes with $>1$ day of treatment; treatment for $>7$ days for $\mathrm{Gl}$ bleeding of any severity; treatment for $>4$ days for severe bleeding (other than GI); treatment for $>3$ days for moderate bleeding (other than GI); treatment for $>2$ days for minor bleeding lother than GI); the last efficacy rating of the bleeding episode was 'moderate' or 'none'.

FVIII, coagulation factor VIII; GI, gastrointestinal; PTP, previously treated patient.

pharmacokinetics and the optimization of dosing regimens for individual patients based on only a few sampling time points. Importantly, for patients on octanate ${ }^{\circledR}$, an octanate $^{\circledR}$-specific population pharmacokinetic model is available in WAPPS.

\section{octanate ${ }^{\circledR}$ is effective in major and minor surgeries}

The efficacy of octanate ${ }^{\circledR}$ as surgical prophylaxis was assessed in 19 surgical procedures in the 14 adult or adolescent patients in the AVI-401/402 surgery study. The patients were aged 1138 years, and all but one were receiving FVIII therapy on-demand at study entry. All patients had a basal FVIII:C of $<1 \%$ and $>100$ previous exposure days (EDs) to FVIII, except one patient with a basal FVIII:C of $2 \%$ and 50 previous EDs. Of the 19 surgical procedures, 6 were classified as major (total hip replacement, arthrodesis of knee, arthroplasty of both knees, total elbow replacement, cholecystectomy and a correction of a talipes equinovarus), 5 as intermediate ( 1 elongation of Achilles tendon, 2 needle liver biopsies and 2 follow-up procedures for removal of orthopaedic devices), and 8 as minor (7 dental extractions and 1 extraction of an ingrown toenail). Continuous infusion was administered in 6 procedures ( 5 of the major surgeries and 1 of the follow-up procedures).

Haemostatic effect was assessed as 'excellent' or 'good' in all 18 evaluated procedures except one $(94.4 \%)$ due to rebleed at the operation site (elbow replacement). For one procedure (arthrodesis of the knee), an efficacy assessment was not possible due to continued bleeding in the postoperative phase, which was due to an open vessel and was not related to the haemostatic efficacy of octanate $^{\circledR}$. The mean (SD) duration of treatment for all procedures was 7.2 (7.1) days (range 1-20 days). Patients received a mean total dose of $18,251.5 \mathrm{IU}$ (range 1000-63,000 IU) of octanate ${ }^{\circledR}$ and a mean dose of $44.6 \mathrm{IU} / \mathrm{kg}$ (range $28.6-$ $68.3 \mathrm{IU} / \mathrm{kg}$ ) per ED.

One additional surgical procedure was performed in a 2-year-old PTP in the AVI-408 study. The patient underwent a surgical intervention for a thoracotomy and haematoma evacuation. The patient received $7000 \mathrm{IU}$ (approximately 535 IU/ $\mathrm{kg}$ ) octanate ${ }^{\circledR}$ as bolus injections over $8 \mathrm{EDs}$, from 3 days prior to the intervention until 4 days after the end of surgery [1000 IU on day 1, 500 IU on days 2 and 3, 2000 IU on day 4 (day of surgery), $1000 \mathrm{IU}$ on days 5 and 6 , and $500 \mathrm{IU}$ on days 7 and 8]. Treatment was assessed as effective in terms of haemostasis and was well tolerated. No major bleeding occurred intra- or postoperatively.

In summary, octanate ${ }^{\circledR}$ provides effective cover during surgery, regardless of surgery type and severity.

\section{octanate $^{\circledR}$ displays low immunogenicity and excellent efficacy in PUPs}

The development of allo-antibodies that neutralize exogenous FVIII, commonly referred to as FVIII inhibitors, remains a major complication of FVIII therapy in the current treatment era. PUPs with severe haemophilia $\mathrm{A}$ are at greatest risk of inhibitor development, with approximately 35\% developing inhibitors, usually within the first 50 EDs, ${ }^{13-16}$ whereas an estimated $1 \%$ of PTPs develop inhibitors. ${ }^{17}$ FVIII inhibitor development is thought to be dependent on a number of 
Table 4. Characteristics of 5 of 51 PUPs who developed FVIII inhibitors in study AVI-403.

\begin{tabular}{|c|c|c|c|c|c|c|}
\hline Patient & Type of inhibitor & $\begin{array}{l}\text { Number of } \\
\text { EDs prior to } \\
\text { detection }\end{array}$ & $\begin{array}{l}\text { Family } \\
\text { history HA/ } \\
\text { inhibitors }\end{array}$ & FVIII gene defect & $\begin{array}{l}\text { Maximum } \\
\text { inhibitor } \\
\text { titre (BU) }\end{array}$ & $\begin{array}{l}\text { Regimen at } \\
\text { time of inhibitor } \\
\text { detection }\end{array}$ \\
\hline 1 & High responding & 6 & No/no & $\begin{array}{l}\text { Large deletions of } \\
\text { exons } 7-12\end{array}$ & 328 & On demand \\
\hline 2 & Transient (high responding) & 19 & No/no & Intron 22 inversion & 7 & On demand \\
\hline 3 & High responding & 3 & Yes/yes & Intron 22 inversion & 445 & On demand \\
\hline 4 & Transient (low responding) & 48 & Yes/no & Intron 22 inversion & 2.1 & On demand \\
\hline 5 & High responding & 11 & No/no & Intron 22 inversion & 29 & On demand \\
\hline
\end{tabular}

BU, Bethesda units; ED, exposure day; FVIII, factor VIII; HA, haemophilia A; PUP, previously untreated patient.

patient- and treatment-related factors; however, none of these definitively predict inhibitor development, making it difficult to assign risk to individual patients and posing challenges in prevention of inhibitor development. ${ }^{18,19}$ One recognised risk factor for inhibitors is the type of $F 8$ gene mutation, with mutations that results in the complete absence of functional FVIII (null mutations) conferring the greatest risk for inhibitor development. ${ }^{20-22}$ Intron-22 and intron-1 inversions and large deletions have been associated with a high risk of inhibitor development, while small insertions and deletions and splice site mutations are usually associated with lower risk. ${ }^{22}$ Another risk factor, which has been a topic of much debate and research in the last decade, is the type of FVIII concentrate, plasma-derived or recombinant, used in the early treatment of patients. While some studies and meta-analyses reported an increased inhibitor risk with recombinant FVIII (rFVIII) derived from hamster cell lines compared with pdFVIII, 16,18,23-27 others found no difference in the risk. ${ }^{13,15,19,28,29}$

The immunogenicity profile of octanate ${ }^{\circledR}$ was evaluated in a prospective, open-label, noncontrolled, multinational, multicentre study (AVI403) in PUPs treated with octanate ${ }^{\circledR} .{ }^{30}$ The study included patients who had received no previous treatment with FVIII-containing products and no inhibitor activity $[<0.6$ Bethesda units (BU)/ $\mathrm{mL}$, with ages ranging from 0.01 to 5.6 years. The primary endpoint of the study was the immunogenicity of octanate ${ }^{\circledR}$ during prophylactic or on-demand treatment over a total of 100 EDs or 5 years, whichever came first. Frequent inhibitor testing was performed at baseline, every 3 or 4 EDs until $20 \mathrm{EDs}$, and thereafter either every 10th ED or every 3 months, whichever came first. Efficacy in the prevention and treatment of bleeds and in surgical prophylaxis, virus safety and tolerability were examined as secondary endpoints.

A total of 51 PUPs were treated with octanate ${ }^{\circledR}$, of whom $80.4 \%$ had an identified high-risk/null F8 mutation (including intron 22 inversions, nonsense/stop/splice site mutations and large deletions). At the end of the study, 46 (90.2\%) patients had $>50$ EDs, 2 (3.9\%) had 20-49 EDs, and $3(5.9 \%)$ had $<20$ EDs.

FVIII inhibitors were detected in 5 of $51(9.8 \%)$ patients; $4(7.8 \%)$ had high-titre inhibitors $(>5 \mathrm{BU} / \mathrm{mL})$ and 1 had a low-titre inhibitor (Table 4). Two of the patients with inhibitors had transient inhibitors that disappeared during regular octanate ${ }^{\circledR}$ treatment without a change in dose or treatment frequency and were not considered clinically relevant. Of note, no FVIII inhibitors developed in PUPs after major surgeries. All patients who developed inhibitors had high-risk/ null F8 mutations: either intron 22 inversions (4 patients) or large deletions (1 patient), and all were treated on-demand. No inhibitors developed in patients with non-null $F 8$ mutations or in patients on prophylaxis.

Of the 51 PUPs in the study, 4 had a baseline FVIII:C level $\geqslant 1 \%$, and 2 patients who did not develop inhibitors had not had 20 EDs, the time by which most inhibitors occur. Excluding these 
Table 5. Efficacy rating per rated injection by reason for administration in PUPs.

\begin{tabular}{llllll}
\hline Rating & $\begin{array}{l}\text { Prophylaxis } \\
(\mathbf{N = 2 6 1 1 )}\end{array}$ & $\begin{array}{l}\text { Treatment of bleeding } \\
\text { episodes }(\boldsymbol{N}=\mathbf{1 8 2 4})\end{array}$ & $\begin{array}{l}\text { Surgery } \\
(\mathbf{N = 2 0 1 )}\end{array}$ & $\begin{array}{l}\text { IVR assessments } \\
(\mathbf{N}=\mathbf{8 0})\end{array}$ & $\begin{array}{l}\text { All administrations } \\
(\mathbf{N}=\mathbf{4 7 1 6})\end{array}$ \\
\hline Excellent & $99.9 \%$ & $99.2 \%$ & $100 \%$ & $100 \%$ & $99.7 \%$ \\
Good & $0.04 \%$ & $0.8 \%$ & - & - & $0.3 \%$ \\
Moderate & - & $0.05 \%$ & - & - & $0.02 \%$ \\
None & - & - & - & - & - \\
\hline IVR, in vivo recovery; & PUP, previously untreated patient. & & \\
\hline
\end{tabular}

patients, and thus applying more stringent criteria, the incidence of inhibitors was $11.1 \%(5 / 45)$ for all inhibitors and $8.9 \%(4 / 45)$ for high-titre inhibitors.

Previously reported FVIII inhibitor incidences from five large epidemiological studies in PUPs treated with pdFVIII concentrates ranged from $20 \%$ to $33 \%$ for all inhibitors, and $12 \%$ to $24 \%$ for high-responding inhibitors. ${ }^{19}$ A recent prospective, randomized, controlled trial, SIPPET, showed a cumulative inhibitor incidence of $44.5 \%$ in PUPs and minimally treated patients treated with rFVIII, compared with $26.8 \%$ in patients treated with $\mathrm{pdFVIII/VWF} .{ }^{14}$ The inhibitor rate observed in the AVI-403 was lower than that observed with pdFVIII/VWF in the SIPPET study, despite there being similar percentages of patients with the null $F 8$ gene mutations in the octanate $^{\circledR}$ study $(80.4 \%)$ as in the SIPPET study $(86.3 \%$ in the $\mathrm{pdFVIII/VWF}$ group and $82.1 \%$ in the rFVIII group).

In the SIPPET study, no inhibitors developed in 16 PUPs with non-null mutations in the $F 8$ gene following treatment with pdFVIII/VWF concentrates, whereas 27 inhibitors developed in 101 $(26.7 \%)$ PUPs with null mutations. ${ }^{31}$ The same pattern was observed in the octanate ${ }^{\circledR}$ PUP study, in that none of the PUPs who developed inhibitors had a non-null $F 8$ gene mutation.

In addition to the low immunogenicity, octanate ${ }^{\circledR}$ demonstrated excellent efficacy in PUPs, consistent with its performance in PTP studies. The haemostatic efficacy of octanate ${ }^{\circledR}$ was overwhelmingly rated as 'excellent' ( $99.7 \%$ of 4716 administrations with available efficacy ratings) (Table 5), and the vast majority of bleeds $(95.5 \%)$ resolved with 1 or 2 days of treatment. Efficacy of all 201 infusions administered for 23 surgical procedures was rated as 'excellent'.

\section{octanate ${ }^{\circledR}$ is successful in ITI therapy in patients with inhibitors}

If inhibitors develop, patients become resistant to FVIII replacement therapy and haemostasis during bleeding episodes and surgical procedures is difficult to establish. This increases the risk of unmanageable bleeding, thereby putting patients in potentially life-threatening situations, and of associated morbidity, such as severe arthropathy and subsequent disability. ITI is the only proven strategy for FVIII inhibitor eradication. Several ITI protocols are currently in use, ${ }^{32-35}$ and there is no consensus on the optimal protocol or FVIII concentrate to be used.

octanate ${ }^{\circledR}$ is one of the FVIII products being evaluated in the ongoing, investigator-initiated, international, open-label, uncontrolled, Observational Immune Tolerance Induction (ObsITI) study. The ObsITI study applies three stringent ITI success criteria to define the efficacy of ITI: inhibitor titre $<0.6 \mathrm{BU} / \mathrm{mL}$; FVIII recovery $\geqslant 80 \%$ of the predefined reference value of $1.5 \% / \mathrm{IU}$ per $\mathrm{kg}$ body weight within $1 \mathrm{~h}$ postinjection; and FVIII half-life $\geqslant 7 \mathrm{~h}$. 'Complete success' requires achievement of all three criteria, 'partial success' requires achievement of two, and 'partial response' requires achievement of one of the three criteria. ITI is considered to have failed if no criteria are met within the 36-month observation period. ${ }^{36}$

Interim data from the prospective arm of the ObsITI study have been reported for a largely poor prognosis cohort of 48 patients who received 


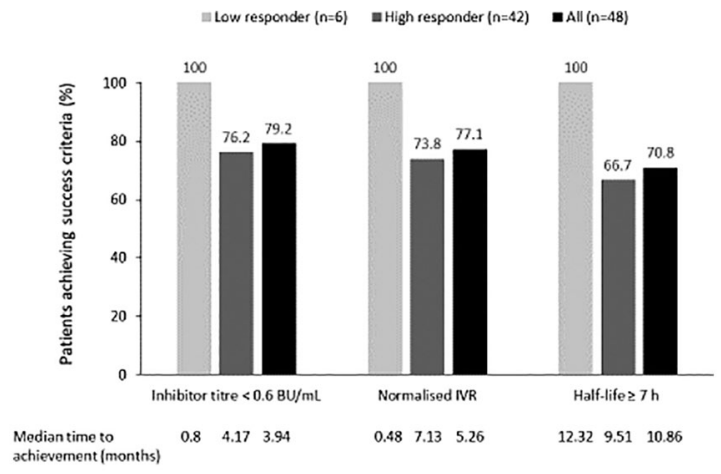

Figure 2. Frequency of achievement of ITI success criteria in ObsITI.

BU, Bethesda units; ITI, immune tolerance therapy; IVR, in vivo recovery; ObsITI, Observational Immune Tolerance Induction study.

ITI with octanate ${ }^{\circledR}$, administered mainly according to the Bonn protocol. ${ }^{36}$ This cohort included both children and adult patients (age range 0.828.1 years); $31.3 \%$ had failed a previous ITI attempt and underwent rescue ITI in the study. Of the 48 patients, $42(87.5 \%)$ had high-titre inhibitors and $6(12.5 \%)$ had low-titre inhibitors. A total of 40 patients $(83.3 \%)$ had at least one risk factor historically associated with a poor ITI prognosis.

Following ITI with octanate ${ }^{\circledR}$, a persistent negative inhibitor titre was achieved in 38 out of 48 patients $(79.2 \%)$, FVIII recovery was normalized in 37 patients $(77.1 \%$ ), and half-life was $\geqslant 7 \mathrm{~h}$ in 34 patients $(70.8 \%)$ (Figure 2$)$. The median time to achievement of these success criteria was short, namely 3.94, 5.26 and 10.86 months, respectively. Complete ITI success was achieved in 34 $(70.8 \%)$ patients; three had partial success $(6.3 \%)$, and one $(2.1 \%)$ a partial response. ITI was unsuccessful in 10 patients (20.8\%). All six patients with low-titre inhibitors and 28 of 42 $(66.7 \%)$ of those with high-titre inhibitors achieved complete success. Furthermore, 22 of 35 patients $(62.9 \%)$ with high-titre inhibitors and $\geqslant 1$ poor prognosis factor achieved complete success. Complete success rate was $60 \%$ (9/15 patients) in those with prior ITI treatment (rescue ITI) versus $75.8 \%$ (25/33 patients) in those without prior ITI (primary ITI).

The study also showed that eradication of inhibitors translated into a clinical benefit: a statistically significant reduction of $86 \%$ in mean monthly bleeding rate was observed following elimination of inhibitors. In the 12 months of follow up, none of the 26 patients who achieved complete success and resumed FVIII prophylaxis had a relapse, showing that ITI with octanate ${ }^{\circledR}$ has a long-lasting tolerizing effect.

The tolerization rate observed in ObsITI is in line with previously published rates for $\mathrm{pdFVIII/VWF}$ concentrates in ITI, which range from $64 \%$ to $94 \% .37-42$ Much lower success rates of approximately $35 \%$ were observed after rFVIII concentrates without VWF became available and were used for ITI, ${ }^{43-46}$ supporting the favourable effect of VWF in terms of decreasing FVIII immunogenicity. Recently, a complete success rate of $55 \%$ was reported in the retrospective Grifols-ITI study analysing ITI success using a pdFVIII/ VWF concentrate in a cohort of 60 patients with severe haemophilia and high-titre inhibitors, largely at high risk of ITI failure. ${ }^{46}$

The time to reach success criteria with octanate ${ }^{\circledR}$, particular negative inhibitor titres, was short. In ObsITI, negative inhibitor titre and complete success were achieved with octanate ${ }^{\circledR}$ in a median of 3.94 months and 10.86 months, respectively. ${ }^{36}$ In the International ITI study of 115 patients with a good ITI risk profile and mostly treated with rFVIII products (102 patients, 90\%), median time to negative inhibitor titre and complete success were 4.6-9.9 months and 10.6-15.5 months (depending on the dose regimen), respectively. ${ }^{47}$ A retrospective chart review of rFVIIIFc $\left(\right.$ Eloctate $^{\circledR}$ ) reported 4 of 7 primary ITI patients achieved negative inhibitor titres in a median of approximately 6 months and complete success in a median of 8 months. ${ }^{48}$ The authors speculated that rFVIIIFc may have properties that uniquely promote tolerization but prospective data are needed before definitive conclusions can be drawn. ${ }^{48}$ Overall, the ObsITI study showed successful management of patients with inhibitors using octanate ${ }^{\circledR}$, and based on these data, octanate $^{\circledR}$ was approved for ITI in haemophilia A patients with inhibitors.

It is important to consider that future ITI protocols might also include nonfactor therapies. ${ }^{49}$ The recently started investigator-initiated, international, low-interventional MOdern Treatment of Inhibitor-PositiVe PATiEnts with Haemophilia A (MOTIVATE) study will evaluate different 
approaches in the management of patients with haemophilia A and inhibitors, including the combination of various FVIII concentrates (among them octanate ${ }^{\circledR}$ ) and emicizumab.

\section{Safety profile of octanate ${ }^{\circledR}$}

The safety profile of octanate ${ }^{\circledR}$ in the PTP studies was consistent with other pdFVIII products, with octanate ${ }^{\circledR}$ being well tolerated and few adverse events (AEs) reported. During 2613 EDs in 85 patients across the five PTP studies, there were a total of 35 AEs, of which 9 were classified as serious and 5 as treatment related. The 5 AEs considered treatment related were malaise in one patient; thrombophlebitis at the infusion site in a surgical patient who had been receiving continuous infusion for 8 days; development of antibodies to parvovirus B19 in two children without any clinical symptoms; and development of a low-titre inhibitor in a surgical patient. A causal relationship between the lowtitre inhibitor and octanate ${ }^{\circledR}$ treatment could not be determined, as the patient had frequently received an alternative FVIII product around the time of inhibitor development. Therefore, no cases of confirmed inhibitor development were reported in PTPs.

A total of 21 AEs were considered probably or possibly related to octanate ${ }^{\circledR}$ in the PUP study: the 5 cases of inhibitor development described above and 16 asymptomatic parvovirus B19 seroconversions. As parvovirus B19 infection is ubiquitous in the general population, it is likely that the 16 children, as well as the 2 PTPs, were exposed through channels other than octanate ${ }^{\mathbb{R}}$ treatment.

In the ObsITI study, octanate ${ }^{\circledR}$ for ITI was well tolerated, with only one adverse drug reaction reported (dermatitis allergica).

Between August 1998 and November 2017, approximately 9.5 million IU of octanate ${ }^{\circledR}$ were sold worldwide. Assuming a mean daily dose of $2000 \mathrm{IU}$, this corresponds to approximately 4.7 million EDs. Inhibitor development (1 report per 677,732 EDs) and hypersensitivity (1 report per $237,206 \mathrm{EDs})$ were very rare $(<1 / 10,000)$, and there were no cases of drug-related thromboembolism.

\section{Conclusions}

Over the past 20 years, the safety and efficacy of octanate $^{\circledR}$ in the prevention and treatment of bleeding in patients with severe haemophilia A have been demonstrated consistently in clinical studies. Available data support the use of octanate ${ }^{\circledR}$ in the treatment of haemophilia $\mathrm{A}$ in a variety of populations, including previously treated adults, adolescents and children, as well as PUPs. The low immunogenicity of octanate ${ }^{\circledR}$ is particularly important for the high-risk previously untreated population. Successful ITI with octanate ${ }^{\circledR}$ was seen in the investigator-initiated ObsITI study, demonstrating the utility of octanate ${ }^{\circledR}$ in patients who develop inhibitors and have a poor prognosis for ITI success. These clinical trial data are supported by the wealth of clinical experience with octanate ${ }^{\circledR}$, which continues to meet the needs of haemophilia A patients for an effective human pdFVIII concentrate with proven low immunogenicity.

\section{Acknowledgement}

The authors thank investigators, trial personnel and patients/carers for their participation in all trials with octanate ${ }^{\circledR}$.

\section{Funding}

The authors disclosed receipt of the following financial support for the research, authorship, and/or publication of this article: Medical writing support was provided by nspm ltd, Meggen, Switzerland, with financial support from Octapharma AG, Lachen, Switzerland.

\section{Conflict of interest statement}

A. Klukowska has received personal fees from CSL Behring, Novo Nordisk, Octapharma, Pfizer, Roche, Shire and Swedish Orphan Biovitrum.

$\mathrm{V}$. Komrska has participated in studies sponsored by Baxalta, Octapharma AG, Shire and Takeda.

$\mathrm{V}$. Vdovin has participated in studies sponsored by Octapharma AG. A. Pavlova has participated in studies sponsored by Octapharma AG.

N. Zozulya has received grants/research support from Octapharma, Baxalta, CSL Behring and Generium and has been a consultant for CSL Behring, Octapharma, Baxalta, Novo Nordisk, Generium and Hoffmann La-Roche.

T. Lissitchkov has received grants or personal fees from Bayer, CSL Behring, Novo Nordisk, 
Octapharma, Roche, Sanofi, Shire and Swedish Orphan Biovitrum.

J. Oldenburg has received reimbursement for attending symposia/congresses or honoraria for speaking or honoraria for consulting, or funds for research from Bayer, Biogen Idec, Biotest, Chugai, CSL Behring, Grifols, Novo Nordisk, Octapharma, Pfizer, Roche, Shire and Swedish Orphan Biovitrum.

C. Escuriola Ettingshausen has received reimbursement for attending symposia/congresses or honoraria for speaking or honoraria for consulting, or funds for research: Alnylam, Baxalta/Shire/ Takeda, Bayer, Biotest, Chugai, CSL Behring, Grifols, Kedrion, Novo Nordisk, Octapharma, Roche and SOBI.

\section{Ethics approval statement}

Ethics approval was not required for this review.

\section{Informed consent statement}

Informed consent was not required for this review.

\section{References}

1. Franchini M. The modern treatment of haemophilia: a narrative review. Blood Transfus 2013; 11: 178-182.

2. Delignat S, Dasgupta S, Andre S, et al. (2007) Comparison of the immunogenicity of different therapeutic preparations of human factor VIII in the murine model of hemophilia A. Haematologica 2007; 92: 1423-1426.

3. Franchini $M$ and Lippi G. Von Willebrand factor-containing factor VIII concentrates and inhibitors in haemophilia A. A critical literature review. Thromb Haemost 2010; 104: 931-940.

4. Terraube V, O'Donnell JS and Jenkins PV. Factor VIII and von Willebrand factor interaction: biological, clinical and therapeutic importance. Haemophilia 2010; 16: 3-13.

5. Orlova NA, Kovnir SV, Vorobiev II, et al. Blood clotting factor VIII: from evolution to therapy. Acta Naturae 2013; 5: 19-39.

6. Brettler B and Levine H. Clinical manifestations and therapy of inherited coagulation factor deficiencies. In: Colman RW (ed.) Hemostasis and thrombosis - basic principles and clinical practice. Philadelphia, PA: JB Lippincott Company, 1994, pp.169-183.
7. World Health Organisation. Delivery of Treatment for Haemophilia - Report of a foint WHO/WFH/ ISTH Meeting. London, United Kingdom, 11-13 February 2002. http://www1.wfh.org/publication/ files/pdf-1451.pdf (accessed 14 November 2019).

8. Bjorkman S, Blanchette VS, Fischer K, et al. Comparative pharmacokinetics of plasma- and albumin-free recombinant factor VIII in children and adults: the influence of blood sampling schedule on observed age-related differences and implications for dose tailoring. F Thromb Haemost 2010: 8: 730-736.

9. Shapiro AD, Korth-Bradley J and Poon MC. Use of pharmacokinetics in the coagulation factor treatment of patients with haemophilia. Haemophilia 2005; 11: 571-582.

10. Octanate Summary of Product Characteristics. https://www.medicines.org.uk/emc/medicine/ 30681 (accessed 14 November 2019).

11. Iorio A, Keepanasseril A, Foster G, et al. Development of a web-accessible population pharmacokinetic service-hemophilia (WAPPSHemo): study protocol. FMIR Res Protoc 2016; 5: e239.

12. McEneny-King A, Foster G, Iorio A, et al. Data analysis protocol for the development and evaluation of population pharmacokinetic models for incorporation into the web-accessible population pharmacokinetic service - hemophilia (WAPPS-Hemo). FMIR Res Protoc 2016; 5: e232.

13. Gouw SC, van der Bom JG, Ljung R, et al. Factor VIII products and inhibitor development in severe hemophilia A. N Engl f Med 2013; 368: 231-239.

14. Peyvandi F, Mannucci PM, Garagiola I, et al. A randomized trial of factor VIII and neutralizing antibodies in hemophilia A. N Engl F Med 2016; 374: 2054-2064.

15. Fischer K, Lassila R, Peyvandi F, et al. Inhibitor development in haemophilia according to concentrate. Four-year results from the European HAemophilia Safety Surveillance (EUHASS) project. Thromb Haemost 2015; 113: 968-975.

16. Vezina C, Carcao M, Infante-Rivard C, et al. Incidence and risk factors for inhibitor development in previously untreated severe haemophilia A patients born between 2005 and 2010. Haemophilia 2014; 20: 771-776.

17. Xi M, Makris M, Marcucci M, et al. Inhibitor development in previously treated hemophilia A patients: a systematic review, meta-analysis, and meta-regression. $\mathcal{F}$ Thromb Haemost 2013; 11 : 1655-1662. 
18. Wight $\mathrm{J}$ and Paisley S. The epidemiology of inhibitors in haemophilia A: a systematic review. Haemophilia 2003; 9: 418-435.

19. Iorio A, Fischer $\mathrm{K}$ and Makris M. Large scale studies assessing anti-factor VIII antibody development in previously untreated haemophilia A: what has been learned, what to believe and how to learn more. Br $\mathcal{F}$ Haematol 2017; 178: 20-31.

20. Carcao MD, van den Berg HM, Ljung R, et al. Correlation between phenotype and genotype in a large unselected cohort of children with severe hemophilia A. Blood 2013; 121: 3946-3952.

21. Bardi E and Astermark J. Genetic risk factors for inhibitors in haemophilia A. Eur $\mathcal{F}$ Haematol 2015; 94(Suppl. 77): 7-10.

22. Gouw SC, van den Berg HM, Oldenburg J, et al. F8 gene mutation type and inhibitor development in patients with severe hemophilia A: systematic review and meta-analysis. Blood 2012; 119 : 2922-2934.

23. Kreuz W, Ettingshausen CE, Auerswald G, et al. Epidemiology of inhibitors and current treatment strategies. Haematologica 2003; 88: EREP04.

24. Goudemand J, Rothschild C, Demiguel V, et al. Influence of the type of factor VIII concentrate on the incidence of factor VIII inhibitors in previously untreated patients with severe hemophilia A. Blood 2006; 107: 46-51.

25. Mancuso ME, Mannucci PM, Rocino A, et al. Source and purity of factor VIII products as risk factors for inhibitor development in patients with hemophilia A. $\mathcal{F}$ Thromb Haemost 2012; 10: 781-790.

26. Iorio A, Halimeh S, Holzhauer S, et al. Rate of inhibitor development in previously untreated hemophilia A patients treated with plasmaderived or recombinant factor VIII concentrates: a systematic review. F Thromb Haemost 2010; 8: 1256-1265.

27. Halimeh S, Bidlingmaier C, Heller C, et al. Risk factors for high-titer inhibitor development in children with hemophilia A: results of a cohort study. Biomed Res Int 2013: 901975.

28. Gouw SC, van der Bom JG, Auerswald G, et al. Recombinant versus plasma-derived factor VIII products and the development of inhibitors in previously untreated patients with severe hemophilia A: the CANAL cohort study. Blood 2007; 109: 4693-4697.

29. Franchini M, Coppola A, Rocino A, et al. Systematic review of the role of FVIII concentrates in inhibitor development in previously untreated patients with severe hemophilia A: a 2013 update. Semin Thromb Hemost 2013; 39: 752-766.

30. Klukowska A, Komrska V, Vdovin V, et al. Low incidence of factor VIII inhibitors in previously untreated patients with severe haemophilia A treated with octanate ${ }^{\circledR}$ : final report from a prospective study. Haemophilia 2018; 24 : 221-228.

31. Rosendaal FR, Palla R, Garagiola I, et al. Genetic risk stratification to reduce inhibitor development in the early treatment of hemophilia A: a SIPPET analysis. Blood 2017; 130: 1757-1759.

32. Batlle J, Lopez MF, Brackmann HH, et al. Induction of immune tolerance with recombinant factor VIII in haemophilia A patients with inhibitors. Haemophilia 1999; 5: 431-435.

33. Brackmann HH, Oldenburg J and Schwaab R. Immune tolerance for the treatment of factor VIII inhibitors - twenty years' 'bonn protocol'. Vox Sang 1996; 70(Suppl. 1): 30-35.

34. Freiburghaus C, Berntorp E, Ekman M, et al. Tolerance induction using the Malmo treatment model 1982-1995. Haemophilia 1999; 5: 32-39.

35. Mauser-Bunschoten EP, Nieuwenhuis HK, Roosendaal G, et al. Low-dose immune tolerance induction in hemophilia A patients with inhibitors. Blood 1995; 86: 983-988.

36. Kreuz W, Escuriola Ettingshausen C, Vdovin $\mathrm{V}$, et al. First prospective report on immune tolerance in poor risk haemophilia A inhibitor patients with a single factor VIII/von Willebrand factor concentrate in an observational immune tolerance induction study. Haemophilia 2016; 22: 87-95.

37. Bidlingmaier C, Kurnik K, EscuriolaEttingshausen C, et al. Immune tolerance induction with a factor VIII concentrate containing von Willebrand factor (Haemoctin $\mathrm{SDH}^{\circledR}$ ) in 14 patients with severe haemophilia A. Haemophilia 2011; 17: e837-840.

38. Greninger DA, Saint-Remy JM, Jacquemin M, et al. The use of factor VIII/von Willebrand factor concentrate for immune tolerance induction in haemophilia A patients with hightitre inhibitors: association of clinical outcome with inhibitor epitope profile. Haemophilia 2008; 14: 295-302.

39. Gringeri A, Musso R, Mazzucconi MG, et al. Immune tolerance induction with a high purity von Willebrand factor/VIII complex concentrate in haemophilia A patients with inhibitors at high 
risk of a poor response. Haemophilia 2007; 13: 373-379.

40. Haya S, Lopez MF, Aznar JA, et al. Immune tolerance treatment in haemophilia patients with inhibitors: the Spanish Registry. Haemophilia 2001; 7: 154-159.

41. Lenk H and ITT Study Group. The German Registry of immune tolerance treatment in hemophilia 1999 update. Haematologica 2000; 85(Suppl. 10): 45-47.

42. Orsini F, Rotschild C, Beurrier P, et al. Immune tolerance induction with highly purified plasmaderived factor VIII containing von Willebrand factor in hemophilia A patients with highresponding inhibitors. Haematologica 2005; 90 : 1288-1290.

43. Kaveri S, Gringeri A, Heisel-Kurth M, et al. Inhibitors in haemophilia A: the role of $\mathrm{VWF} /$ FVIII concentrates-a meeting report. Haemophilia 2009; 15: 587-591.

44. Kreuz W, Steiner JJ, Mentzer D, et al. Successful immune tolerance therapy of FVIII-inhibitors in children after changing from high to intermediate purity FVIII concentrate. Ann Hematol 1996; 72(Suppl. 1): 339.
45. Auerswald G, Spranger T and Brackmann $\mathrm{HH}$. The role of plasma-derived factor VIII/von Willebrand factor concentrates in the treatment of hemophilia A patients. Haematologica 2003; 88: EREP05.

46. Oldenburg J, Jiménez-Yuste V, Peiró-Jordán $\mathrm{R}$, et al. Primary and rescue immune tolerance induction in children and adults: a multicentre international study with a VWF-containing plasma-derived FVIII concentrate. Haemophilia 2014; 20: 83-91.

47. Hay CR and DiMichele DM; International Immune Tolerance Study Group. The principal results of the International Immune Tolerance Study: a randomized dose comparison. Blood 2012; 119: 1335-1344.

48. Carcao M, Shapiro A, Staber JM, et al. Recombinant factor VIII Fc fusion protein for immune tolerance induction in patients with severe haemophilia A with inhibitors-A retrospective analysis. Haemophilia 2018; 24: 245-252.

49. Carcao M, Escuriola-Ettingshausen C, Santagostino E, et al. The changing face of immune tolerance induction in haemophilia A with the advent of emicizumab. Haemophilia 2019; 25: 676-684. 